\title{
Infections caused by extended-spectrum beta-lactamases producing Enterobacteriaceae: clinical and economic impact in patients hospitalized in 2 teaching hospitals in Dakar, Senegal
}

\author{
Awa Ndir ${ }^{1,2,5^{*}}$, Amadou Diop ${ }^{3}$, Roughyatou Ka ${ }^{4}$, Pape Makhtar Faye ${ }^{3}$, Ndeye Mery Dia-Badiane ${ }^{4}$, \\ Babacar Ndoye $e^{5}$ and Pascal Astagneau ${ }^{6}$
}

\begin{abstract}
Background: Infections caused by extended-spectrum beta-lactamases producing Enterobacteriaceae (ESBL-E) are of major concern in clinical practice because of limited therapeutic options effective to treat them. Published studies showed that ESBL-E, widely spread in Europe, United States or Asia; are also frequent in Africa. However, the impact of ESBL-E infections is yet to be adequately determined in Sub-Saharan African countries, particularly in Senegal. The aim of our study was to estimate the incidence rate of ESBL-E infections and to assess their clinical and economic impact in Senegal.

Methods: Two retrospective cohort studies were conducted in patients hospitalized from April to October 2012. A classic retrospective cohort study comparing patients infected by an Enterobacteriaceae producer of ESBL (ESBL+) and patients infected by an Enterobacteriaceae non-producer of ESBL (ESBL-) was carried out for fatal outcomes. Besides, a retrospective parallel cohort study comparing infected patients by an ESBL+ and ESBL- versus uninfected patients was carried out for the excess LOS analyses. Multivariable regression analysis was performed to identify risk factors for fatal outcomes. A multistate model and a cost-of-illness analysis were used to estimate respectively the excess length of stay (LOS) attributable to ESBL production and costs associated. Cox proportional hazards models were used to assess the independent effect of ESBL+ and ESBL- infections on LOS.
\end{abstract}

Results: The incidence rate of ESBL-E infections was 3 cases/1000 patient-days (95 \% Cl: 2.4-3.5 cases/1000 patient-days). Case fatality rate was higher in ESBL+ than in ESBL- infections ( $47.3 \%$ versus $22.4 \%, p=0.0006$ ). Multivariable analysis indicated that risk factors for fatal outcomes were the production of ESBL (OR $=5.7,95 \% \mathrm{Cl}: 3.2-29.6, p=0.015)$ or being under mechanical ventilation ( $\mathrm{OR}=5.6,95 \% \mathrm{Cl}: 2.9-57.5, p=0.030)$. Newborns and patients suffering from meningitidis or cancer were patients at-risk for fatal outcomes. ESBL production increased hospital LOS (+4 days) and reduced significantly the hazard of discharge after controlling for confounders ( $H R=0.3,95 \%$ Cl:0.2-0.4). The additional cost associated with ESBL-production of €100 is substantial given the lower-middle-income status of Senegal.

Conclusion: Our findings show an important clinical and economic impact of ESBL-E infections in Senegal and emphasize the need to implement adequate infection control measures to reduce their incidence rate. An antibiotic stewardship program is also crucial to preserve the effectiveness of our last-resort antibiotic drugs.

Keywords: ESBL, Enterobacteriaceae, Antibiotic resistance, Impact, Economic, Africa, Cost-of-illness, Multistate model

\footnotetext{
*Correspondence: ndir.awa@gmail.com

${ }^{1}$ PhD Program, Université Pierre Marie Curie, Paris, France

${ }^{2}$ Institut Pasteur de Dakar, Epidemiology unit, Dakar, Senegal

Full list of author information is available at the end of the article
} 


\section{Background}

Extended-spectrum beta-lactamases producing Enterobacteriaceae (ESBL-E) are of major concern since infections caused by these resistant strains are associated with prolonged hospital stay and increased case-fatality rate [1-3]. ESBL-E became a significant therapeutic challenge worldwide in daily clinical practice since their resistances to additional classes of antibiotics reduce effective therapeutic options [4-6]. However, the increased use of carbapenems, drugs of last-resort to treat these infections, favors the emergence of carbapenem-resistant Enterobacteriaceae [7-9]. It is therefore crucial to better understand the extent of the threat poses by ESBL-E and to quantify its burden in order to help policymakers and healthcare professionals to set priorities and implement effective countermeasures. In Africa published studies showed that ESBL-E prevalence rate is increasing and is varying from $0.7 \%$ in Malawi to 75.8 \% in Egypt $[10,11]$. However, until now the burden of ESBL-E has not been clearly established especially in sub-Saharan African countries.

This study aimed to estimate the incidence rate of ESBL-E infections and to assess the clinical and economic consequences of these infections in two hospitals in Dakar, Senegal.

\section{Methods}

\section{Study design and population}

Two retrospective cohort studies were carried out in patients hospitalized from April to October 2012 at the University Hospital of Fann and Albert Royer Children's hospital, 2 academic tertiary care hospitals located in the same geographic area in Dakar, Senegal (respectively a 339-Bed and 120-bed hospitals). A classic retrospective cohort study comparing patients infected by an Enterobacteriaceae producer of ESBL (ESBL+) and patients infected by an Enterobacteriaceae non-producer of ESBL (ESBL-) was carried out for fatal outcomes. Besides, a retrospective parallel cohort study comparing infected patients (ESBL+ or ESBL- infections) versus uninfected patients was carried out for excess LOS analyses. Patients with an infection caused by an Enterobacteriaceae strain were identified through a laboratory-based surveillance of strains recovered from diagnostic samples taken at least $48 \mathrm{~h}$ after the patient admission when an infection was suspected. The date of the infection onset was the date the first sample yielding an Enterobacteriaceae strain was collected. If a bacterial strain was isolated on several occasions, only the first isolation was considered. Uninfected patients were randomly selected from the hospital database system. Inclusion criteria for the group of uninfected patients were the absence of clinical signs of an infection reported in patients' medical files, the absence of diagnostic samples drawn and antibiotics prescriptions during the hospital stay. Infected and uninfected patients were matched on ward and day of admission. All patients included in the study were followed from admission to discharge or in-hospital death. For each patient, the following variables were collected: gender, age, germs isolated and their resistance profile, underlying comorbidities, diagnostic at admission, interventions related to patient care before the infection onset, length of stay, date of infection onset, antibiotic prescriptions during the hospital stay and in-hospital mortality.

\section{Definitions}

Newborns were defined as patients less than 28 days of life and included premature babies (babies born before 37 weeks of gestational age). Children were patients aged between 1 month and 16 years and adults were patients up to 16 years.

An infection was suspected if clinical signs of the infection were observed by the clinician and was bacteriologically confirmed when a bacterial strain was recovered from diagnostic samples. In newborns and children, an infection was suspected in the presence of fever $\left(>=38{ }^{\circ} \mathrm{C}\right)$, hypothermia $\left(<36{ }^{\circ} \mathrm{C}\right)$ or other signs of infection as detailed in the World Health Organization (WHO) guideline of the Integrated Management of Childhood Illness [12]. Infections were defined as ESBL+ when the sample yielded an ESBL-producing Enterobacteriaceae (ESBL-E) and ESBL- when Enterobacteriaceae was nonproducer of ESBL. Antimicrobial therapy was defined as empirical if prescribed initially before susceptibility tests results were available. Initial antibiotic therapy was considered as inadequate when the empirical antibiotic drug was not active against the pathogen causing the infection.

\section{Microbiological methods}

Enterobacteriaceae strains were Gram strained and then identified with API 20E strips (bioMérieux, Marcy l'Etoile, France). Susceptibilities against antimicrobial agents and the detection of ESBL production were routinely performed in the two hospitals by the disc diffusion synergy method using discs containing cefepime, ceftazidime and cefotaxime each placed $30 \mathrm{~mm}$ apart around a disc containing clavulanic acid as recommended by the Antibiogram Committee of the French Microbiology Society [13].

\section{Statistical analysis}

Continuous variables were compared using Student's $t$ test with unequal variances. Fisher's exact test was used for the comparison of categorical variables.

To evaluate risk factors for fatal outcomes, a multivariable model was constructed using a backward stepwise logistic regression analysis including all variables with a 
$p$-value less than 0.20 in the univariate analysis. $P$ value less than 0.05 was considered as significant.

\section{Multistate model}

The excess LOS attributable to ESBL production was estimated using a multistate model in which the occurrence of the infection was the time-dependent exposure, while the discharge (alive or dead) was the study endpoint (Fig. 1). Patients enter in the multistate model in state 1 at hospital admission. At the time of infection (ESBL+ or ESBL- infection) patients move to state 2 then to state 3 at the time of discharge or death. Patients who do not experience an infection during their hospital stay move directly from state 1 to state 3 . The excess LOS attributable to ESBL production was the difference between LOS due to ESBL+ and ESBL- infections. When assessing the LOS due to ESBL+ infections, patients with an ESBL+ infection were compared to patients free of infection including uninfected patients and patients with an ESBL- infection but the latter were administratively censored at the time of infection. Likewise, patients with an ESBL+ infection were administratively censored when assessing the LOS due to ESBL- infection $[14,15]$.

Transition probabilities to move from one state to another were estimated non-parametrically using the AalenJohansen estimator [15-17]. The expected LOS was then computed by a function of the Aalen-Johansen estimator for the matrix of transition probabilities. The mean difference in LOS was computed for each day in the interval, as the difference between the estimated LOS given the intermediate state had been reached or not up that day. Standard errors and confidence intervals were calculated by 500 bootstrap resampling runs $[15,18,19]$.

To assess the independent effect of ESBL+ and ESBLinfections on LOS, they were separately evaluated as time-dependent covariates using Cox proportional hazards modeling to estimate the end-of-LOS hazard ratio (HR). Variables for adjustment included age, comorbidities and invasive devices.
The $\mathrm{R}$ packages msm and etm were used for LOS analysis (version 2.15.3). All other statistical analyses were performed using Stata software, release 13.0.

\section{Cost-of-illness analysis}

A cost-of-illness (COI) analysis was performed to quantify the cost associated with ESBL production from the patient perspective. Only direct medical costs incurred by patients from the date of the infection onset were measured. Indirect costs such as lost wages resulting from death or the absence from work were not considered in our analysis. A bottom-up approach was used to calculate the resources spent to treat the infection. Therefore total cost related to an infection (ESBL+ or ESBL+ infection) included costs of hospital stay, laboratory diagnostic tests and antibiotic drugs prescriptions. The cost of the hospital stay was calculated by multiplying the excess LOS attributable to the infection (estimated by multistate modeling) by the bed-day cost. For the costs related to diagnostic tests we considered the inclusive fee of $€ 25$ charged for all laboratory tests performed on a patient during the hospital stay, regardless of their number and nature. The dosage and duration of antibiotic drugs prescriptions to treat the infection were collected from patients' medical files. The drug prices used for the calculations differ according to whether drugs were bought at the subsidized hospital pharmacy or purchased in private pharmacies.

\section{Ethical considerations}

This study protocol was approved by the hospital's institutional review board. Since the data were routinely collected and anonymized, ethical consent was not required.

\section{Results}

Characteristics of the study patients

During the 6-month study period, 186 Enterobacteriaceae strains were isolated in patients with a suspected infection. ESBL-E ( $\mathrm{n}=110)$ were Klebsiella spp $(49.1 \%)$, Enterobacter

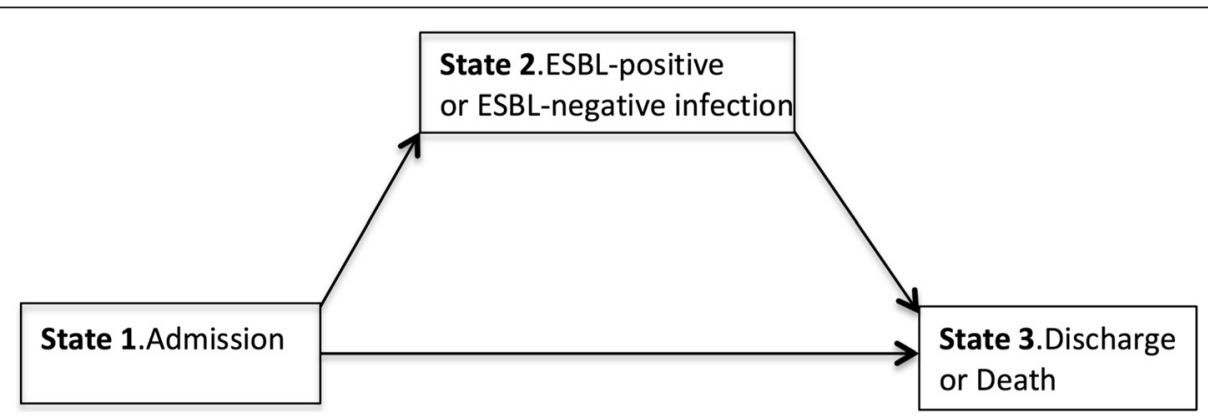

Fig. 1 Multistate model used for the excess length of stay analysis. Every patient enters the model in state 1 on the day of admission, make a transition into state 2 at the time of infection (ESBL+ or ESBL-) then move to the 3 at the time of discharge or death. Uninfected patients enter in state 1 and move to state 3 without transition through state 2 
Table 1 Baseline characteristics of patients infected by Enterobacteriaceae producer of ESBL $(E S B L+)$ and Enterobacteriaceae non-producer of ESBL (ESBL-)

\begin{tabular}{|c|c|c|c|}
\hline Variable, n (\%) & $\begin{array}{l}\text { ESBL+ infections } \\
(n=110)\end{array}$ & $\begin{array}{l}\text { ESBL- infections } \\
(n=76)\end{array}$ & $P$-value \\
\hline \multicolumn{4}{|l|}{ Demographics } \\
\hline Male gender & $68(61.8)$ & $35(46.05)$ & 0.037 \\
\hline Mean age, years (range) & $26.3(20.9-31.7)$ & $28.1(21.5-34.7)$ & 0.665 \\
\hline Newborns (0-28 days) & $22(20.0)$ & $4(5.3)$ & 0.005 \\
\hline Premature babies & $12(10.9)$ & $2(2.6)$ & 0.046 \\
\hline $\begin{array}{l}\text { Children } \\
\text { (1 month-17 years) }\end{array}$ & $37(33.6)$ & $34(44.7)$ & 0.167 \\
\hline Adults (up to 17 years) & $51(46.4)$ & $38(50.0)$ & 0.656 \\
\hline \multicolumn{4}{|l|}{ Comorbidity } \\
\hline Sickle cell disease & $10(9.1)$ & $7(9.2)$ & 1 \\
\hline Malnutrition & $10(9.1)$ & $7(9.2)$ & 1 \\
\hline AIDS & $8(7.2)$ & $2(2.6)$ & 0.203 \\
\hline \multicolumn{4}{|l|}{ Diagnostic at admission } \\
\hline Severe malaria & 19(17.3) & $7(9.2)$ & 0.808 \\
\hline Gastroenteritis & $16(14.5)$ & $9(11.8)$ & 0.666 \\
\hline Respiratory disease & $25(22.7)$ & 10(9.1) & 0.127 \\
\hline Neurologic disorder & $20(18.2)$ & $12(15.8)$ & 0.698 \\
\hline Meningitis & $10(9.1)$ & $5(4.5)$ & 0.596 \\
\hline Tuberculosis & $3(2.7)$ & $3(3.9)$ & 0.689 \\
\hline Cancer & $10(9.1)$ & $6(7.9)$ & 1 \\
\hline Tetanus & $4(3.6)$ & $6(7.9)$ & 0.321 \\
\hline \multicolumn{4}{|l|}{ Invasive procedure } \\
\hline Surgical intervention & 18(16.4) & $18(23.7)$ & 0.258 \\
\hline Parental nutrition & $24(21.8)$ & $6(7.9)$ & 0.014 \\
\hline Mechanical ventilation & $38(34.5)$ & $7(9.2)$ & $<0.0001$ \\
\hline Central venous catheter & $84(76.4)$ & $35(46.0)$ & $<0.0001$ \\
\hline Urinary catheter & 37(33.6) & 13(17.1) & 0.018 \\
\hline \multicolumn{4}{|l|}{ Type of infection } \\
\hline Bloodstream infection & $49(44.5)$ & $20(26.3)$ & 0.013 \\
\hline Urinary tract infection & $36(32.7)$ & $31(40.8)$ & 0.279 \\
\hline Surgical site infection & 13(11.8) & $11(14.4)$ & 0.656 \\
\hline Respiratory infection & $5(4.5)$ & $12(15.8)$ & 0.016 \\
\hline Meningitidis & $7(6.4)$ & $2(2.6)$ & 0.313 \\
\hline \multicolumn{4}{|l|}{$\begin{array}{l}\text { Time to infection, } \\
\text { in days }(95 \% \mathrm{Cl})\end{array}$} \\
\hline All patients & $8.2(6.4-9.9)$ & $4.8(2.7-6.9)$ & 0.007 \\
\hline Adults & 11.3(8.8-13.8) & $7.7(4.8-10.6)$ & 0.029 \\
\hline Children & $6.6(3.1-10.2)$ & $2(1.2-5.2)$ & 0.028 \\
\hline Newborns & $3.5(2.2-4.8)$ & $1(0.3-2.3)$ & 0.059 \\
\hline
\end{tabular}

spp (28.2 \%) and E.coli $(22.7 \%)$. The incidence rate of ESBL-E was 3 cases/1000 patient-days (95 \% CI: 2.4-3.5 cases/1000 patient-days). The characteristics of the study patients are described in Table 1 . The study population was constituted of 110 patients with an ESBL+ infection, 76 patients with an ESBL- infection and 186 uninfected patients. ESBL-E was most frequently associated with bloodstream infections (44.5\%), urinary tract infections (32.7\%) and surgical site infections (11.8 \%) (Table 1).

\section{Fatal outcomes}

Sixty-nine patients with an infection caused by an Enterobacteriaceae died during the study period (37.1\%). The case-fatality rate was significantly higher in ESBL+ $(47.3 \%)$ than in ESBL- infections $(22.4 \%)(p=0.0006)$. Patients who died were most frequently newborns, premature babies, patients who suffered from meningitidis or cancer, patients with an ESBL+ infection and patients with invasive devices such as mechanical ventilation or central venous catheter (Table 2).

Multivariable analysis showed that the production of ESBL (OR $=5.3,95 \% \mathrm{CI}: 3.1-19.9, p=0.008)$ or being under mechanical ventilation $(\mathrm{OR}=6.1,95 \% \mathrm{CI}$ : $3.1-$ 124.6, $p=0.004$ ) were independent risk factors for fatal outcomes. Results also showed that newborns and patients suffering from meningitidis or cancer were patients at-risk for fatal outcomes (Table 2).

\section{Length of stay (LOS)}

Then mean LOS associated with ESBL+ and ESBL- infections was respectively 22.6 days (95\% CI: 20.3-24.9 days) and 14 days (95 \% CI: 11.9-16.2 days). The mean time to infection was significantly longer in patients with an ESBL+ than an ESBL- infection except in newborns (Table 1). However, when comparing patient's groups, the mean time to infection was shorter in newborns (3.5 days) than in children (6.6 days) or adults (11.3 days). Besides, the hospital stay after the infection was significantly longer in ESBL+ than in ESBL- infections (14.4 versus 9.3, $p<0,0001)$ suggesting that ESBL production prolonged the hospital LOS. Results presented in 
Table 2 Risk factors for fatal outcomes: results of univariate and multivariable analyses

\begin{tabular}{|c|c|c|c|c|c|c|c|c|}
\hline \multirow[t]{2}{*}{ Variable, $n(\%)$} & \multicolumn{2}{|l|}{ Fatal outcomes } & \multicolumn{3}{|c|}{ Univariate analysis } & \multicolumn{3}{|c|}{ Multivariable analysis } \\
\hline & Yes $(n=69)$ & No $(n=117)$ & OR & $95 \% \mathrm{Cl}$ & $P$-value & OR & $95 \% \mathrm{Cl}$ & $P$-value \\
\hline \multicolumn{9}{|l|}{ Demographics } \\
\hline Male gender & $34(49.3)$ & 49(41.9) & 1.3 & $0.7-2.4$ & 0.361 & & & \\
\hline Mean age, years (range) & 27.1(20.4-33.8) & $26.9(21.6-32.3)$ & & & 0.489 & & & \\
\hline Newborns (0-28 days) & $16(23.2)$ & $10(8.5)$ & 3.2 & $1.4-7.5$ & 0.008 & 4.5 & $2.4-37.8$ & 0.025 \\
\hline$P$ remature babies & $9(13.0)$ & $5(4.3)$ & 3.4 & $1.1-9.9$ & 0.042 & & & \\
\hline Children (1 month-17 years) & $17(24.6)$ & $54(46.1)$ & 2.6 & $1.4-5.0$ & 0.005 & & & \\
\hline Adults (up to 17 years) & $36(52.2)$ & $53(45.3)$ & 1.3 & $0.7-2.4$ & 0.448 & & & \\
\hline \multicolumn{9}{|l|}{ Comorbidity } \\
\hline Sickle cell disease & $6(8.7)$ & $11(0.5)$ & 0.5 & $0.3-2.5$ & 1 & & & \\
\hline Malnutrition & $4(5.8)$ & $13(11.1)$ & 0.5 & $0.5-1.5$ & 0.296 & & & \\
\hline AIDS & $3(4.3)$ & $7(5.9)$ & 0.7 & $0.2-2.6$ & 0.747 & & & \\
\hline \multicolumn{9}{|l|}{ Diagnostic at admission } \\
\hline Gastroenteritis & $6(8.7)$ & $19(16.2)$ & 0.5 & $0.2-1.3$ & 0.184 & & & \\
\hline Respiratory disease & $18(26.1)$ & $17(14.5)$ & 2.1 & $0.9-4.3$ & 0.079 & & & \\
\hline Meningitis & $11(15.9)$ & $4(3.4)$ & 5.3 & $1.7-16.6$ & 0.004 & 2.3 & $1.5-4.9$ & $<0.0001$ \\
\hline Tuberculosis & $2(2.8)$ & $4(3.4)$ & 0.8 & $0-4.1$ & 1 & & & \\
\hline Cancer & $12(20.3)$ & $4(3.4)$ & 5.9 & $1.9-18.3$ & 0.002 & 2.7 & $1.6-6.6$ & 0.001 \\
\hline Neurologic disorder & $8(11.5)$ & $24(20.5)$ & 0.5 & $0.2-1.2$ & 0.159 & & & \\
\hline \multicolumn{9}{|l|}{ Invasive procedure } \\
\hline Surgical intervention & $15(21.7)$ & $21(17.9)$ & 1.3 & $0.6-2.6$ & 0.567 & & & \\
\hline Parenteral nutrition & $15(21.7)$ & $15(12.8)$ & 1.9 & $0.9-4.1$ & 0.148 & & & \\
\hline Mechanical ventilation & $28(40.5)$ & $17(14.5)$ & 3.9 & $1.9-7.9$ & 0.0002 & 6.1 & $3.1-124.6$ & 0.040 \\
\hline Central venous catheter & $53(76.8)$ & $66(56.4)$ & 2.6 & $1.3-4.9$ & 0.007 & & & \\
\hline Urinary catheter & $14(20.3)$ & $36(30.8)$ & 0.6 & $0.3-1.1$ & 0.128 & & & \\
\hline ESBL Production & $52(75.4)$ & $58(49.6)$ & 3.1 & $1.6-5.9$ & $<0.0001$ & 5.3 & $3.1-19.9$ & 0.008 \\
\hline \multicolumn{9}{|l|}{ Type of infection } \\
\hline Bloodstream infection & $31(44.9)$ & $38(32.5)$ & 1.7 & $0.9-3.1$ & 0.116 & & & \\
\hline Urinary tract infection & $18(26.1)$ & 49(41.9) & 0.5 & $0.2-0.9$ & 0.039 & & & \\
\hline Meningitidis & $7(10.1)$ & $2(1.7)$ & 6.5 & $1.5-25.7$ & 0.014 & & & \\
\hline Surgical site infection & $9(13.0)$ & 15(12.8) & 1.0 & $0.4-2.4$ & 1 & & & \\
\hline Respiratory infection & $4(6.8)$ & $8(7.7)$ & 0.8 & $0.2-2.7$ & 1 & & & \\
\hline Inadequate antibiotherapy prescription & 49(71.0) & $62(52.9)$ & 2.3 & $1.2-4.3$ & 0.013 & & & \\
\hline Mean time to infection, days, $(95 \% \mathrm{Cl})$ & $5.9(4.3-7.5)$ & 7.3(5.4-9.3) & & & 0.838 & & & \\
\hline
\end{tabular}

Table 3 indicated that ESBL production was associated with an excess LOS of 4 days (95\% CI: 3.8-4.6) and decreased significantly the hazard of discharge after adjustment for confounding (HR:0.3, 95 \% CI:0.2-0.4). However, ESBL- infections did not decrease significantly the hazard of being discharged (HR:0. 9, $95 \%$ CI:0. 7-1.2).

\section{Cost-of-illness analysis}

The cost-of-illness (COI) analysis indicated a mean hospital cost significantly greater in ESBL+ (€215, 95 \% CI:
$€ 196-233)$ than in ESBL- infections (€115, $95 \% \mathrm{CI}$ : $€ 103-123), p<0.0001$. Thus, the additional cost attributable to ESBL production was $€ 100$ (95 \% CI: €78-€125). Hospital stay and antibiotic drugs accounted respectively for 60 and $40 \%$ of this cost.

\section{Discussion}

Our study quantifies the economic impact of ESBL-E infections in patients admitted in 2 hospitals in Senegal. The additional cost of $€ 100$ attributable to the ESBL 
Table 3 Estimation of the excess length of stay (LOS) and hazard ratios (HR) of discharge associated with ESBL+ and ESBLinfection

\begin{tabular}{llll}
\hline & & \multicolumn{2}{l}{ HR of discharge } \\
\cline { 3 - 4 } & $\begin{array}{l}\text { Excess LOS, } \\
\text { days }(95 \% \mathrm{Cl})\end{array}$ & $\begin{array}{l}\text { Univariate } \\
(95 \% \mathrm{Cl})\end{array}$ & $\begin{array}{l}\text { Multivariable } \\
(95 \% \mathrm{Cl})\end{array}$ \\
\hline ESBL+ infection $^{\text {a }}$ & $7.9(7.6-9.2)$ & $0.3(0.2-0.4)$ & $0.3(0.2-0.4)$ \\
ESBL- infection $^{\text {b }}$ & $3.9(3.8-4.6)$ & $0.9(0.7-1.2)$ & $0.9(0.7-1.2)$ \\
\hline
\end{tabular}

Cl confidence interval

${ }^{\text {a } M o d e l ~ A: ~ E x c e s s ~ L O S ~ d u e ~ t o ~ E S B L+~ i n f e c t i o n ~}$

110 patients with ESBL+ infection versus 76 patients with ESBL- infection

censored at time of infection and 186 uninfected patients

${ }^{b}$ Model B: Excess LOS due to ESBL- infection

Seventy-six patients with ESBL- infection versus 110 patients with ESBL+ infection censored at time of infection and 186 uninfected patients

production may appear as low compared to costs reported in high-income countries, which vary from $€ 5$, 000 to $€ 14,720[1,2,20,21]$. The difference in costs could be explained firstly by the high cost of equipment used in high-income countries, and secondly by the variability in methods used to estimate the economic impact of ESBL-E infections. Indeed, the occurrence of the infection considered as time-fixed in studies that compare infected patients with uninfected patients and the use of median values have been demonstrated to overestimate costs [22]. We avoided those pitfalls in our cost-of-illness (COI) analysis by comparing patients with ESBL+ and ESBL- infections versus uninfected patients, by considering the infection as time-dependent and measuring mean values. Costs were estimated from the patient's perspective and not from the hospital or third-party payer perspective as frequently found in the literature. Indeed in Senegal, hospital costs are most of the time entirely outlaid by patients since only $20 \%$ of the population has a healthcare coverage. Costs associated with ESBL+ or ESBL- infections might be considerable for some patients, since these costs are respectively 2.5-times and 1.3-times higher than the mean monthly salary $(€ 87)$ in the country [23]. These out-of-pocket expenses can be crippling for alreadyimpoverished households, pushing them further into poverty $[24,25]$. Kruk et al. demonstrated that $37.8 \%$ (95 \% CI: 30.7-45.5) of Senegalese households often resort to "hardship financing" defined as borrowing money from family, friends or selling their assets to cover hospital costs [26].

Besides, the hospital charges attributable to ESBL production would be more burdensome if antimicrobial therapy such as imipenem was prescribed. A 7-day treatment by imipenem would lead to an additional cost of $€ 400$. The choice of appropriate antibiotic drugs is crucial to treat ESBL-E infections; however, hospital stay was found to be the major driver of costs and could represent up to $60 \%$ of costs as previously shown [21]. The time-dependent nature of infections should be taken into account when assessing the excess LOS attributable to a multidrug resistant pathogen. Indeed, it has been shown that the time-dependent bias will inevitably overestimate the impact of the infection on LOS and consequently on hospital costs [27, 28]. Therefore, we used a multistate model that accounts for time-varying exposure thereby avoiding the time-dependent bias inherent in other commonly used statistical methods [15, 28-30]. Results of the multistate model revealed an excess LOS attributable to ESBL production of 4 days (95\% CI: 3.8-4.6). Results of the Cox proportional hazards models showed a significant reduction in hazard of discharge associated with ESBL+ infections after adjustment on confounders and consequently a prolonged hospital stay.

Furthermore, the high rate of inadequate initial antimicrobial therapy (IIAT) in ESBL+ infections might delay the initiation of adequate therapy and consequently explain the prolonged LOS and the significant impact of ESBL+ infections on fatal outcomes demonstrated in our study $[31,32]$. Indeed, the unavailability of imipenem in pharmacies or its unaffordability to the majority of patients may increase the risk of therapeutic failure in severe ESBL+ infections and thereby the risk of fatal outcomes. Our results suggest to adapt the current antibiotic prescriptions' guidelines to the local bacterial epidemiology and to restrict the frequent empirical use of $3^{\text {rd }}$ generation cephalosporins.

The multistate model can be considered as a suitable approach when assessing the excess LOS attributable to ESBL production. However, while taking into account the time-dependent bias, the excess LOS may still be biased by other covariates. Besides, our findings should be interpreted with cautious since we could not collect data on prior antibiotic exposure that may potentially underestimate the incidence rate of ESBL+ infections. Additionally our results cannot be generalized to the whole hospitals in Senegal since our study was carried out only in two hospitals.

Despite these limitations, our findings should increase the awareness of healthcare decision makers on the threat poses by ESBL-E infections. Besides, these results should incite them to implement adequate infection prevention and control policies to reduce the incidence rate and the clinical and economic impact of ESBL-E infections. The assessment of the level of hand hygiene practices realized during the study period in the two hospital settings using a WHO tool [33] showed a basic level of hand hygiene suggesting that some measures were in place but not to a satisfactory standard. An infection control program including the promotion of alcoholbased handrub (ABHR) use should be implemented in these hospitals in order to improve their hand hygiene levels and to decrease the incidence rate of ESBL-E infections. Indeed, hand washing using alcohol-based handrub (ABHR) has been shown to be successful to reduce the incidence rate of antimicrobial resistant 
pathogens [34-36]. To ensure the availability of expensive ABHR in resource-poor countries, the WHO African Partnerships for Patient Safety program have launched a program in the two study settings for the local production of ABHR [37]. Additionally, since the human digestive tract is the main reservoir of Enterobacteriaceae strains, measures specifically targeting ESBL-E, such as the management of excreta, should also be implemented.

\section{Conclusion}

We show that ESBL-E are frequent in Senegal and that infections caused by these multiresistant pathogens increase the case-fatality rate and the hospital length of stay of hospitalized patients and consequently have an important financial impact for patients. Our findings are a call for action to healthcare policymakers to consider multidrug resistance as a national health priority and to implement adequate infection control measures to tackle this worldwide issue. Surveillance surveys should be implemented in Sub-Saharan African countries in order to have a more accurate estimate of the global extent of ESBL-E, which threaten the effectiveness of our last-resort drugs.

\section{Competing interests}

The authors declare that they have no competing interests.

\section{Authors' contributions}

AN conceived, designed the study, coordinated the data collection, performed statistical analysis and wrote the manuscript. AD led the laboratory work and helped for the preparation of the manuscript. RK led the laboratory work and help for the preparation of the manuscript. PMF was involved in the data collection and the review of medical records. NDB was involved in the data collection and the review of medical records. BN contributed to the conception of the study and made substantial contributions in drafting the manuscript. PA contributed to the conception and design of the study, supervised the study, interpreted data analysis, and made substantial contributions in drafting the manuscript and revising it critically. All authors read and approved the final version of the manuscript.

\section{Acknowledgments}

We thank Yaye Dior Dieng and Koumou Onanga for the data collection, the Directors of the two study settings, the heads of the microbiology laboratories and the hospital administrative teams for their helpful support. We are grateful to Momar Dieng and Vincent Richard for their critical review of the manuscript. We also thank Cheikh Loucoubar for his contribution in statistical analyses performed.

\section{Author details}

${ }^{1}$ PhD Program, Université Pierre Marie Curie, Paris, France. ${ }^{2}$ Institut Pasteur de Dakar, Epidemiology unit, Dakar, Senegal. ${ }^{3}$ Hôpital pour Enfants Albert Royer, Dakar, Senegal. ${ }^{4}$ Centre Hospitalier Universitaire de Fann, Dakar, Senegal. ${ }^{5}$ Infection Control Africa Network, Cape Town, South Africa. ${ }^{6}$ Universités Sorbonne Paris-Cité, Paris, France.

Received: 17 June 2015 Accepted: 10 April 2016

Published online: 18 April 2016

\section{References}

1. Lautenbach E, Patel JB, Bilker WB, Edelstein PH, Fishman NO. Extended-spectrum $\beta$-lactamase-producing Escherichia coli and Klebsiella pneumoniae: risk factors for infection and impact of resistance on outcomes. Clin Infect Dis. 2001;32:1162-71.

2. Schwaber MJ, Navon-Venezia S, Kaye KS, Ben-Ami R, Schwartz D, Carmeli Y. Clinical and economic impact of bacteremia with extended-spectrum beta-lactamase producing Enterobacteriaceae. Antimicrob Agents Chemother. 2006;50:1257-62.

3. Paterson DL, Bonomo R. A. Extended-spectrum $\beta$-lactamases: a clinical update. Clin Microbiol Rev. 2005:18:657-86.

4. Lautenbach E, Strom BL, Bilker WB, Patel JB, Edelstein PH, Fishman NO. Epidemiological investigation of fluoroquinolone resistance in infections due to extended-spectrum beta-lactamase-producing Escherichia coli and Klebsiella pneumoniae. Clin Inf Dis. 2001;32:1162-71.

5. Hyle EP, Lipworth AD, Zaoutis TE, Nachamkin I, Fishman NO, Bilker WB, et al. Risk factors for Increasing multidrug resistance among Extended-Spectrum B-Lactamase-producing Escherichia coli and Klebsiella species. Clin Infect Dis. 2005:40:1317-24.

6. Schwaber MJ, Navon-Venezia S, Schwartz D, Carmeli Y. High levels of antimicrobial coresistance among extended-spectrum beta-lactamase producing Enterobacteriaceae. Antimicrob Agents Chemother. 2005;49:2137-9.

7. Nordmann P, Naas T, Poirel L. Global spread of carbapenemase-producing Enterobacteriaceae. Emerg Infect Dis. 2011;10:1791-8.

8. Falagas ME, Karageorgopoulos DE, Nordmann P. Therapeutic options with Enterobacteriaceae producing carbapenem-hydrolyzing enzymes. Future Microbiol. 2011;6:653-6.

9. Nordmann P, Cuzon G, Naas T. The real threat of Klebsiella pneumoniae carbapenemase-producing bacteria. Lancet Inf Dis. 2009;9:228-36.

10. Storberg V. ESBL producing Enterobacteriaceae in Africa - a non systematic literature review of research published 2008-2012. Infect Ecol Epidemiol. 2014;4:2032.

11. Tansarli GS, Poulikakis P, Kapaskelis A, Falagas ME. Proportion of extendedspectrum bet-lactamases (ESBL)-producing isolates among Enterobacteriaceae in Africa: evaluation of the evidence-systematic review. J Antimicrob Chemother. 2014;69:1177-84.

12. World Health Organization. Handbook Integrated Management of Childhood Illness. 2005. Available from:http://www.who.int/maternal_child_ adolescent/documents/9241546441/en/If applicable, please provide the access dates of references 12, 13, 23, 33 and 37.Not applicable

13. Société Française de Microbiologie. European Society of Clinicial Microbiology and Infectious Diseases. Comité de l'antibiothérapie de la Société Française de Microbiologie. Recommendations. 2015. Available from: http://www.sfm-microbiologie.org/UserFiles/files/casfm/CASFM_ EUCAST_V1_2015.pdf.

14. Stewardson A, Fankhauser C, De Angelis G, Rohner P, Safran E, Schrenzel J, et al. Burden of bloodstream infection caused by extended-spectrum betalactamase-producing Enterobacteriaceae determined using multistate modeling at a Swiss University Hospital and a nationwide predictive model. Infect Control Hosp Epidemiol. 2013;34:133-43.

15. De Angelis G, Allignol A, Murthy A, Wolkewitz M, Beyersmann J, Safran E, et al. Multistate modelling to estimate the excess length of stay associated with meticillin-resistant Staphylococcus aureus colonisation and infection in surgical patients. J Hosp Infect. 2011;78:86-91.

16. Aalen $\mathrm{O}$, Johansen $\mathrm{S}$. An empirical transition matrix for non-homogeneous Markov chains based on censored observations. Scand J Stat. 1978:5:141-50.

17. Datta S, Satten GA. Validity of the Aalen-Johansen estimators of stage occupation probabilities and Nelson-Aalen estimators of integrated transition hazards for non-Markov models. Statist Probabil Lett. 2001;55:403-11.

18. Efron B, Tibshirani R. Bootstrap methods for standard errors, confidence intervals and other measures of statistical accuracy. Statist Sc. 1986;1:54-77.

19. Beyersmann J. A random time interval approach for analyzing the impact of a possible intermediate event on a terminal event. Biometr J. 2007:49:742-9.

20. Tumbarello M, Spanu T, Di Bidino R, Marchetti M, Ruggeri M, Trecarichi EM, et al. Costs of bloodstream infections caused by Escherichia coli influence of extended-spectrum beta-lactamase production and inadequate initial antibiotic therapy. Antimicrob Agents Chemother. 2010;54:4085-91.

21. Lee SY, Kotapati S, Kuti JL, et al. Impact of Extented-Spectrum betaLactamase-Producing Escherichia coli and Klebsiella species on clinical outcomes and hospital costs: a matched cohort study. Infect Control Hosp Epidemiol. 2006;27:1226-32.

22. Gandra S, Barter DM, Laxminarayan R. Economic burden of antibiotic resistance: how much do we really know? Clin Micro Inf. 2014;20:973-9.

23. Worldbank data indicators. Available from:http://data.worldbank.org/indicator.

24. Burke RM, Rebolledo PA, Embrey SR, Wagner LD, Cowden CL, Kelly FM, et al. The burden of pediatric diarrhea: a cross-sectional study of incurred costs and perceptions of cost among Bolivian families. BMC Public Health. 2013;13:708. 
25. Bhojani U, Thriveni BS, Devadasan R, Munegowda CM, Devadasan N, Kolsteren P, et al. Out-of-pocket healthcare payments on chronic conditions impoverish urban poor in Bangalore, India. BMC Public Health. 2012;12:990.

26. Kruk ME, Goldmann E, Galea S. Borrowing and selling to pay for health care in a low and middle-income country. Health Aff. 2009;28:1056-66.

27. De Angelis G, Murthy A, Beyersmann J, Harbarth S. Estimating the impact of healthcare-associated infections on length of stay and costs. Clin Micro Inf. 2010;16:1729-35.

28. Barnett AG, Beyersmann J, Allignol A, Rosenthal VD, Graves N, Wolkewitz M. The time-dependent bias and its effect on extra length of stay due to nosocomial infection. Value Health. 2011;14:381-6.

29. Beyersmann J, Kneib T, Schumacher M, Gastmeier P. Nosocomial infection, length of stay, and time-dependent bias. Infect Control Hosp Epidemiol. 2009;30:273-6

30. Schumacher M. An easy mathematical proof showed that time-depended bias is inevitably leads to biased effect estimation. J Clin Epidemiol. 2008;61:1216-21.

31. Tumbarello M, Sanguinetti M, Montuori E, Trecarichi EM, Posteraro B, Fiori B, et al. Predictors of mortality in patients with bloodstream infections caused by extended-spectrum beta-lactamase producing Enterobacteriaceae: importantce of inadequate initial antimicrobial treatment. Antimicrob Agents Chemother. 2007:51:1984-94.

32. Hyle EP, Lipworth AD, Zaoutis TE, Nachamkin I, Bilker WB, Lautenbach E. Impact of inadequate initial antimicrobial therapy on mortality in infections due to extended-spectrum beta-lactamase producing Enterobacteriaceae: variability by site of infection. Arch Intern Med. 2005:165:1375-80.

33. World Health Organization. Hand hygiene self-assessment framework. http:// www.who.int/gpsc/country_work/hhsa_framework_October_2010.pdf.

34. Hilburn J, Hammond BS, Fendler EJ, Groziak PA. Use of alcohol hand sanitizer as an infection control strategy in an acute care facility. Am J Infect Control. 2003;31:109-16.

35. Cimiotti JP, Stone PW, Larson EL. A cost comparison of hand hygiene regimes. Nurs Econ. 2004;22:196-9. 204,175.

36. Jarlier V, Trystram D, Brun-Buisson C, et al. Curbing methicillin resistant Staphylococcus aureus in 38 French hospitals through a 15-year institutional control program. Arch Intern Med. 2010;170:552-9.

37. World Health Organization. African Patient Safety Program. Available from: http://who.int/patientsafety/implementation/apps/events/ABHR-workshopreport.pdf.

\section{Submit your next manuscript to BioMed Central and we will help you at every step:}

- We accept pre-submission inquiries

- Our selector tool helps you to find the most relevant journal

- We provide round the clock customer support

- Convenient online submission

- Thorough peer review

- Inclusion in PubMed and all major indexing services

- Maximum visibility for your research

Submit your manuscript at www.biomedcentral.com/submit

CBiomed Central 